\title{
Magnitude and correlates of sleep quality among undergraduate medical students in Ethiopia: cross -sectional study
}

Tirusew Wondie ${ }^{1 *} \mathbb{D}$, Alemayehu Molla ${ }^{2}$, Haregewoin Mulat ${ }^{3}$, Woynabeba Damene ${ }^{4}$, Mengistu Bekele ${ }^{4}$, Derebe Madoro $^{2}$ and Kalkidan Yohannes ${ }^{2}$

\begin{abstract}
Purpose: Poor quality of sleep has a negative effect on academic performance of medical students. Quantity and quality of sleep in addition to average sleep time are strongly linked with students' learning abilities, poor academic performance and poor interpersonal relationship which predispose them to mental illnesses. This study is aimed to assess magnitude and correlates of sleep quality among medical students in Ethiopia.

Method: An institutional based cross-sectional study was conducted among 576 undergraduate medical students. Data was collected by using interviewer administered structured questionnaires. Pittsburgh Sleep Quality Index (PSQl) was used to assess sleep quality. The collected data were entered in to Epi-data version 3.1and analyzed using SPSS version 20. Logistic regression was used to identify the potential determinants of quality of sleep among undergraduate medical students. P-values less than 0.05 were considered statistically significant and strength of the association was presented by adjusted odds ratio with 95\% C.I.

Result: The prevalence of poor sleep quality among undergraduate medical students was $62 \%(95 \% \mathrm{Cl}, 57.9,65.3)$. The mean age $( \pm S D)$ of the respondents was $21.5( \pm 2.4)$, with age ranging from 18 to 28 and about $310(53.8 \%)$ were males. Factors like, being depressed $(A O R=1.92,95 \% \mathrm{Cl} 1.16,3.19)$, poor social support $(A O R=5.39,95 \% \mathrm{Cl} 2.33$, 2.49), being stressed $(A O R=2.04,95 \% \mathrm{Cl} 1.26,3.31)$, and poor sleep hygiene $(A O R=3.01,95 \% \mathrm{Cl} 1.75,5.18)$ were associated with poor sleep quality at $p$-value $<0.05$. Findings also showed that, one unit increase in grade point average was associated with $81.5 \%$ decrease $(\mathrm{AOR}=0.185,95 \% \mathrm{Cl} 0.13,0.28)$ in poor sleep quality.

Conclusion: A substantial proportion of medical students are affected by poor sleep quality. Routine screening of sleep quality, sleep hygiene, depression and stress is warranted. Moreover, it is better to educating medical students about proper sleep hygiene and the consequences of poor sleep.
\end{abstract}

Keywords: Sleeps quality, Medical students, Ethiopia

\section{Introduction}

Adequate sleep is important for maintaining good physical, mental, and emotional health and is one of the most important factor to the quality of life (Abiola et al. 2013; Ezquiaga et al. 2015). Sleep quality is phenomenon which is difficult to define and is measured by both

\footnotetext{
* Correspondence: wondietirusew21@gmail.com

${ }^{1}$ Department of Psychiatry College of medicine and health science, Debre Markos University, Debre Markos, Ethiopia

Full list of author information is available at the end of the article
}

quantitative and qualitative components (Rodrigues et al. 2002). Sleep duration and the timing of sleep also influence cognitive performance. Sleep timing depends on both the length of prior wakefulness and on the control of the circadian clock (Genzel et al. 2013). Poor sleep quality can be a symptom of mental illnesses and many chronic physical illnesses, but can also be a common health problem for medical students (Foley et al. 2004; Dixon et al. 2003; Foster et al. 2013; Hyyppä and Kronholm 1989; Yang et al. 2003; Yazdi et al. 2016). The

(c) The Author(s). 2021 Open Access This article is licensed under a Creative Commons Attribution 4.0 International License, which permits use, sharing, adaptation, distribution and reproduction in any medium or format, as long as you give appropriate credit to the original author(s) and the source, provide a link to the Creative Commons licence, and indicate if changes were made. The images or other third party material in this article are included in the article's Creative Commons licence, unless indicated otherwise in a credit line to the material. If material is not included in the article's Creative Commons licence and your intended use is not permitted by statutory regulation or exceeds the permitted use, you will need to obtain permission directly from the copyright holder. To view a copy of this licence, visit http://creativecommons.org/licenses/by/4.0/. 
prevalence of poor sleep quality is high in both developing and high income societies (Shad et al. 2015; Azad et al. 2015). WHO report showed that about $27 \%$ of people suffer from sleep problems in worldwide (Yang et al. 2003). The studies also showed that 50 to 70 million people are chronically suffering from sleep disorders (Stranges et al. 2012; Altevogt and Colten 2006).

Medicine is one of the most stressful fields of education because of its highly demanding study which may be why poor sleep quality is common among medical students. Its prevalence is twofold high among medical students as compared to general populations (Azad et al. 2015; Brown et al. 2001; Waqas et al. 2015). Medical students have a more stressful academic program related to long duration of study year, high intensity of study, overnight clinical duties (Abdulghani et al. 2012; Sahraian and Javadpour 2010; Wong et al. 2005). A review study conducted in Brazil showed that 51.5\%, of medical students had poor sleep quality (Pacheco et al. 2017). In US $50.9 \%$ of medical students had poor sleep quality (Brick et al. 2010). Study conducted in developing countries showed that $32.5-76 \%$ of medical students suffer from poor sleep quality (James et al. 2011; Almojali et al. 2017). Study conducted in Ethiopia among non-medical students and adults in community showed 55.8 and $65.4 \%$ of participants had poor quality of sleep respectively (Berhanu et al. 2018; Lemma et al. 2012).

Poor sleep quality among medical students have significant impact on mental and physical health, lead to problem of drinking and suicidal thought which adversely affects academic performance and influence the community in the form of accidents and medical error (Mume et al. 2011; Kenney et al. 2012; Nadorff et al. 2011).

As we tried to revise details of literatures done among medical students in different countries; correlates like, coffee or tea, excessive use of social media, use of drugs, medical problems, irregular sleep schedule, depression, anxiety, academic performance and gender were associated with poor sleep quality in different studies (Azad et al. 2015; Haseli-Mashhadi et al. 2009; Lund et al. 2010a). Factors like, poor social support and poor sleep hygiene were also add as determinants of poor sleep quality among medical students.

Studies showed that medical students are very susceptible to develop poor sleep as compared with nonmedical students due to more stressful academic program, to the long duration of study year, high intensity of study, clinical duties, emotionally challenging work, that include overnight duties affect their habits of sleep (Azad et al. 2015; James et al. 2011; Dahl and Lewin 2002; Surani et al. 2015a; Yeung et al. 2008). In Ethiopia medical students are also over stressed, because they learn intensive period of their lives and even they have limited health break time as compared with non-medical students. Despite this, as per the investigators' knowledge; there is no specific study among medical students in Ethiopia.

Therefore, this study is aimed to assess magnitude and correlates of poor sleep quality among medical students in Tikur Anbessa Specialized hospital, is first hospital in Ethiopia which addresses students coming from all regions of Ethiopia. Intervention focused to factors of poor sleep quality is important to maintain concentration, sensorimotor integration, and memory processing to medical students (Vyazovskiy 2015).

\section{Methods and materials \\ Study design and setting}

Institutional based cross-sectional study was conducted from May 1-June 8, 2019. The study was conducted in Tikur Anbessa Specialized hospital which is found in Lideta sub city in Addis Ababa and it is the largest referral hospital in the country with more than 700 beds. It was transferred to the school by the federal ministry of health, and it became university teaching hospital for both clinical and preclinical training of most discipline. Hospital addresses students of year one up to year six coming from all parts of Ethiopia and in hospital a total of 20,100 students are learning medical science.

\section{Study population}

The study participants were selected from all undergraduate medical students (year one up to year six) at Tikur Anbessa Specialized Hospital. Participants who were ill with difficulty of communication during the study period were excluded.

\section{Sample size determination and sampling procedure}

The sample size was calculated with the following assumptions: margin of error 4, at 95\% CI, the prevalence of poor sleep quality $61.4 \%$ which was taken from similar study from Sudan (Mirghani et al. 2015). After adding $10 \%$ non-response rate the final calculated sample size was 626. To assure representativeness of the sample, proportional allocation was done to the respective class year. The list of students was obtained from college registrar and computer generated simple random sampling method was used to select each study participants from their respective group.

\section{Data collection and tools}

Data was collected by using interviewer administered structured questionnaires. It was collected by three BSc psychiatry nurses and regularly supervised by one mental health professional.

Socio-demographic characteristics like; age, sex, marital status, year of the study and average cumulative grade 
point were collected by semi-structured sociodemographic questionnaires. Substance related factors were assessed by WHO ASSIST (alcohol smoking and substance involvement screening tool). In this study we considered current use of substance like khat, alcohol, cigarette and others. Participants with response of yes for either of substance use for non-medical purpose were considered as they use substance for that respective substance (Kessler et al. 1998) An outcome variable, Sleep quality was assessed by using Pittsburgh Sleep Quality Index (PSQI); the instrument has been validated among college students in sub-Saharan Africa (Aloba et al. 2007). The PSQI is composed of 19 questions which evaluate sleep in the past 1 month. The PSQI provides seven component scores which measures subjective sleep quality, sleep latency, sleep duration, habitual sleep efficiency, sleep disturbances, daytime dysfunction and use of sleep medications. The score for each component ranges from 0 to 3 ; with 3 indicating the greatest dysfunction. A total global PSQI is derived by summing the seven components; higher scores indicating poor sleep quality and it ranged from 0 to 21. Based on prior literature students with PSQI score greater than 5 was labeled as having poor sleep quality and those with PSQI score less than or equal to 5 was labeled as having good sleep quality (Buysse et al. 1989). Internal consistence (Cronbach alpha) of PSQI in current study is 0.78 . The sleep hygiene was assessed by a 13 item sleep hygiene index (SHI) questionnaire with components of taking day time nap for more than $2 \mathrm{~h}$, going to bed in different time form day to day, using caffeine or stimulants while going to bed, going to bed while feeling stressed and related items. Each item is rated on a five-point scale ranging from 0 (never) to 4 (always). Total scores range from 0 to 52, and participants with score of greater than16 were considered as having poor sleep hygiene (Mastin et al. 2006; Ozdemir et al. 2015). Internal consistence (Cronbach alpha) in current study was 0.74 .

Social support was collected by Oslo-3 item social support scale, it is 3 item questionnaires, commonly used to assess social support and it has been used in several studies, the sum score scale ranging from 3 to 14, which has 3 categories: poor support 3-8, moderate support 9-11 and strong support 12-14 (Dalgard et al. 2006).

Depression, anxiety, and stress were measured using Lovibond and Lovibond's short version of the depression Anxiety stress scale (DASS-21). The questions inquire the experience of the items in the past week and each item is scored from 0 (did not apply to me at all) to 3 (applied to me very much). The values obtained were multiplied by two to obtain score and finally score of 10 and above for depression, score of 8 and above for anxiety and score of 15 and above for stress were considered as participants had depression anxiety and stress (Szabó
2010). The internal consistency (Cronbach's alpha) in current study was as follows; (DASS21-D subscale 0.91; DASS21-A subscale 0.72.; and DASS21-Ssubscale 0.82.).

\section{Statistical analysis}

Coded and checked data were entered into the computer using EPI Data version 3.1 and imported to statistical package for social science (SPSS) window software version 20. Descriptive statistics such as (frequency, percentage and mean) were computed and presented using tables to show picture of the data. Bivariate binary logistic analysis was performed to determine each of explanatory variables with outcome variable (quality of sleep) and variables with $\mathrm{p}$ - value less than 0.2 during bivariate analysis were entered to multivariate analysis. Multivariate binary logistic regression analysis was conducted to determine the presence of a statistically significant association between explanatory variables and outcome variables. Finally variables with $P$ values less than 0.05 were considered statistically significant and strength of the association was presented by adjusted odds ratio with $95 \%$ C.I.

\section{Results}

Socio-demographic characteristics of respondents

A total of 576 participants were included in the study with the response rate of $92 \%$. The mean age $( \pm$ SD) of the respondents was $21.5( \pm 2.4)$, with age ranging from 18 to 28 years and about $294(51 \%)$ of the respondents were $\leq 21$ years and also about 310 (53.8\%) were males. Educational status of the students indicated that about $128(22 \%)$ of respondents were fourth year. Regarding marital status, large numbers of the respondents were single $(94.1 \%)$ and the mean of cumulative grade was $2.81 \pm 0.59$ (Table 1$)$.

\section{Clinical, substance and social factors of the respondents} From participants, 369 (64.1\%) and 322(55.9\%) had symptom of depression and stress respectively. Nearly half of 277(48.1\%) respondents had poor sleep hygiene. Regarding substance related factors about 236 (41\%) of the respondents use alcohol currently within 3 months and $280(48.6 \%)$ of the respondent reported that they had poor social support, (Table 2).

\section{Magnitude of poor sleep quality and its components scores among the respondents}

According to this study, among a total of included 576 students 357 [62\% (95\%CI, 58.2, 65.8)] of medical students have poor sleep quality. Regarding to the sleep latency, about 156 (27.1\%), of participants had sleep latency of 16-30 min. The median amount of sleep latency was $25 \mathrm{~min}$, and only $65(11.3 \%)$ of participants slept greater than $7 \mathrm{~h}$ per night. When assessment was limited 
Table 1 Socio demographic characteristics among undergraduate medical students at Tikur Anbessa Specialized hospital, Addis Ababa, Ethiopia, 2019 ( $N=576)$

\begin{tabular}{lll}
\hline Variables & Frequency & Percent \\
\hline Sex & 310 & 53.8 \\
Male & 266 & 45.2 \\
Female & & \\
Age & 282 & 49 \\
$>21$ & 294 & 51 \\
$\leq 21$ & & \\
Marital status & 34 & 5.9 \\
Married & 542 & 94.1 \\
Single & & \\
Year of Education & 112 & 19.4 \\
First year & 85 & 14.8 \\
Second year & 108 & 18.8 \\
Third year & 128 & 22.2 \\
Fourth year & 69 & 12.0 \\
Fifth year & 74 & 12.8 \\
Six year & & $2.81 \pm 0.59$ \\
Cumulative grade & & \\
Mean + Standard deviation & & \\
\hline
\end{tabular}

to the component item of sleep quality tool, about 136 $(23.6 \%)$ of the students stated that their subjective experience of sleep quality was very bad. The use of medication for sleep in three or more times a week was reported by $49(8.5 \%)$ of the participants, (Table 3$)$.

\section{Factors associated with quality of sleep}

In bi-variable logistic analysis variables; sex, current alcohol use, current Khat use, depression, stress, anxiety, sleep hygiene, social support and CGPA were found to have $p$-value less than 0.2 . These variables fulfilled minimum requirements for further multivariable logistic regression.

In multivariable logistic regression variables; depression, stress, sleep hygiene, poor social support and CGPA were statistically significant with poor sleep quality at p-value less than 0.05 .

The odds of having poor sleep quality among respondents who are depressed were 1.9 times higher as compared to non-depressed respondents $(\mathrm{AOR}=1.92$, 95\%CI,1.92(1.16,3.19). Respondents who had poor sleep hygiene were 3 times more likely to have poor sleep quality as compared to those with good sleep hygiene $(\mathrm{AOR}=3.01,95 \% \mathrm{CI}(1.75,5.18)$. The odds of having poor sleep quality among participants with stress was 2 times higher as compared with their counterparts $(\mathrm{AOR}=2.04$, $95 \% \mathrm{CI}, 1.26,3.31)$.
Table 2 Clinical, Substance and Social factors among undergraduate medical students at Tikur Anbessa Specialized hospital, Addis Ababa, Ethiopia, $2019(N=576)$

\begin{tabular}{|c|c|c|}
\hline Variables & Frequency & Percent \\
\hline \multicolumn{3}{|l|}{ Depression } \\
\hline Yes & 369 & 64.1 \\
\hline No & 207 & 35.9 \\
\hline \multicolumn{3}{|l|}{ Anxiety } \\
\hline Yes & 315 & 54.7 \\
\hline No & 261 & 45.3 \\
\hline \multicolumn{3}{|l|}{ Stress } \\
\hline Yes & 322 & 55.9 \\
\hline No & 254 & 44.1 \\
\hline \multicolumn{3}{|c|}{ Sleep hygiene } \\
\hline good & 299 & 51.9 \\
\hline poor & 277 & 48.1 \\
\hline \multicolumn{3}{|c|}{ Current cigarette use } \\
\hline No & 544 & 94.4 \\
\hline Yes & 32 & 5.6 \\
\hline \multicolumn{3}{|c|}{ Current khat use } \\
\hline No & 518 & 89.9 \\
\hline Yes & 58 & 10.1 \\
\hline \multicolumn{3}{|c|}{ Current alcohol use } \\
\hline not use & 340 & 59 \\
\hline Use & 236 & 41 \\
\hline \multicolumn{3}{|c|}{ Social support } \\
\hline Poor & 280 & 48.6 \\
\hline Moderate & 174 & 30.2 \\
\hline Strong & 122 & 21.2 \\
\hline
\end{tabular}

Regarding social support, participants with poor social support were 5.4 times more likely to have poor sleep quality as compared with respondents who had strong social support $(\mathrm{AOR}=5.39,95 \% \mathrm{CI}, 2.33,12.49)$. CGAP was also another factor which associated with quality sleep. As average grade point of students increase in a unit, poor sleep quality decreases/changes by $81.5 \%$ [AOR $=0.185,95 \%$ CI $(0.13,0.28)]$, (Table 4$)$.

\section{Discussion}

The study was conducted among medical students in Tikur Anbessa specialized hospital, which is first and well known specialized hospital; address students coming from all regions of country. As our knowledge this is the first study regarding sleep quality and associated factors among medical students in our country.

In this study the prevalence of poor sleep quality was $62 \%(95 \% \mathrm{CI}, 57.9,65.3)$ which was consistent with the study conducted in Sudan 61.4\% (Mirghani et al. 2015) and Iraq 60.4\% (Al-Humairi 2018). However, result of 
Table 3 Sleep quality and its component score among undergraduate medical students at Tikur Anbessa Specialized hospital, Addis Ababa, Ethiopia, 2019 ( $N=576)$

\begin{tabular}{|c|c|c|}
\hline Components & Frequency & Percent \\
\hline \multicolumn{3}{|l|}{ Sleep latency } \\
\hline 0 & 141 & 24.5 \\
\hline 1 & 156 & 27.1 \\
\hline 2 & 132 & 22.9 \\
\hline 3 & 147 & 25.5 \\
\hline \multicolumn{3}{|l|}{ Sleep duration } \\
\hline.$>7 \mathrm{~h}$ & 65 & 11.3 \\
\hline $6-7 h$ & 220 & 38.2 \\
\hline $5-6 h$ & 39 & 6.8 \\
\hline$<5 \mathrm{~h}$ & 252 & 43.8 \\
\hline \multicolumn{3}{|l|}{ Sleep efficiency (\%) } \\
\hline$>85$ & 270 & 46.9 \\
\hline $75-84$ & 115 & 20.0 \\
\hline $65-74$ & 71 & 12.3 \\
\hline$>65$ & 120 & 20.8 \\
\hline \multicolumn{3}{|l|}{ Day time dysfunction } \\
\hline 0 & 188 & 32.6 \\
\hline 1 & 84 & 14.6 \\
\hline 2 & 148 & 25.7 \\
\hline 3 & 156 & 27.1 \\
\hline \multicolumn{3}{|l|}{ Sleep disturbance } \\
\hline 0 & 114 & 19.8 \\
\hline 1 & 194 & 33.7 \\
\hline 2 & 148 & 25.7 \\
\hline 3 & 120 & 20.8 \\
\hline \multicolumn{3}{|l|}{ Subjective sleep quality } \\
\hline Very good & 184 & 31.9 \\
\hline Fairly good & 124 & 21.5 \\
\hline Fairly bad & 132 & 22.9 \\
\hline Very bad & 136 & 23.6 \\
\hline \multicolumn{3}{|l|}{ Use of sleep medication } \\
\hline Not during the past month & 294 & 51.0 \\
\hline Less than once a week & 80 & 13.9 \\
\hline Once or twice a week & 153 & 26.6 \\
\hline Three or more times a week & 49 & 8.5 \\
\hline \multicolumn{3}{|l|}{ Sleep quality score } \\
\hline Good sleep & 219 & 38.0 \\
\hline Poor sleep & 357 & 62.0 \\
\hline
\end{tabular}

the present study was higher than the study reported among non-medical students in Ethiopia 55.8\% (Lemma et al. 2012), Nigeria 32\% (James et al. 2011), Iran 57.5\%, (Yazdi et al. 2016) central India 32.53\% (Rathi et al.
2018), Pakistan Karachi 39.5\% (Surani et al. 2015b), Brazil 51.5\% (Pacheco et al. 2017) and US 50.9\%. (Brick et al. 2010) On the other hand, our study was lower than the previous studies done in India 67.42\%, (Priya et al. 2017) Saudi Arabia 70.4-76\% (Almojali et al. 2017; Siddiqui et al. 2016; Ibrahim et al. 2017), India 72.9\% (Shad et al. 2015) and Pakistani 77\% (Waqas et al. 2015). The possible reasons for the variability could be due to differences in sampling technique, which was consecutive sampling technique used in Pakistan Karachi and systematic and meta-analysis study was conducted in Brazil. Socio-cultural difference might be other reasons for this difference. Study population also might have its contribution for variation since study conducted in Nigeria used only 5 and 6 years of medical students, in Central India first and second year medical students were study participants. It is fact that medical students had class over load than non-medical students, this might be the possible reason for high prevalence of poor sleep quality among medical students than non- medical students in Ethiopia.

The second objective of this study was to identify factors associated with poor sleep quality among medical students. The correlates associated with poor sleep quality were selected based on our professional experience in our country and revision of previous similar studies. The significant association was found between stress and poor sleep quality among medical students. This is similar to the finding of study conducted in Pakistan (Waqas et al. 2015) and Saudi Arabia (Almojali et al. 2017), Physiologically, many studies have found that sleep and stress are closely linked to the hypothalamus- pituitary adrenal (HPA) axis (Kashani et al. 2012; Van Reeth et al. 2000a), which may explain the close relationship between these two variables (Van Reeth et al. 2000b). Acute stress is accompanied by a decrease in slow wave, raped eye movement and increase sleep deprivation (Van Reeth et al. 2000b).

In this study the odds of having poor sleep quality among depressed respondents was 2 times higher as compare to non-depressed responders. This finding coincides with results from Virginia (Lund et al. 2010b), Egypt (Fawzy and Hamed 2017) and Saudi Arabia (Ibrahim et al. 2017). The possible reason might be depression decreases neurotransmitter serotonin and results in diminished cognitive performance that affect normal sleep pattern (Sadock and Ruiz 2014).

The study revealed that the CPGA is a significant predictor of sleep quality, this is consistent to previous study in Iraq (Al-Humairi 2018) and Saudi Arabia. The possible justification for this might be poor academic performance may adversely affect sleep through concomitant stress and also students with poor academic performance spend more hours at night for reading 
Table 4 Logistic regression showing association between factors and sleep quality among undergraduate medical students at Tikur Anbessa specialized hospital Addis Ababa Ethiopia, 2019 ( $N=576)$

\begin{tabular}{|c|c|c|c|c|}
\hline \multirow{2}{*}{$\begin{array}{l}\text { Explanatory } \\
\text { variables }\end{array}$} & \multicolumn{2}{|l|}{ Sleep quality } & \multirow{2}{*}{$\begin{array}{l}\text { Crude Odds } \\
\text { ratio }(95 \% \text { ci) }\end{array}$} & \multirow{2}{*}{$\begin{array}{l}\text { Adjusted Odds } \\
\text { ratio }(95 \% \text { ci) }\end{array}$} \\
\hline & Poor $(n=357)$ & Good $(n=219)$ & & \\
\hline \multicolumn{5}{|l|}{ Sex } \\
\hline Female & 189 & 77 & $2.08(1.47,2.93)$ & $1.48(0.93,2.36)$ \\
\hline Male & 168 & 142 & 1.00 & 1.00 \\
\hline \multicolumn{5}{|c|}{ Current alcohol use } \\
\hline Yes & 154 & 82 & $1.27(0.89,1.79)$ & $1.22(0.78,1.92)$ \\
\hline No & 203 & 137 & 1.00 & 1.00 \\
\hline \multicolumn{5}{|c|}{ Current khat use } \\
\hline Yes & 41 & 17 & $1.54\left(0.85,2.79^{`}\right)$ & $1.91(0.89,4.06)$ \\
\hline No & 316 & 202 & 1.00 & 1.00 \\
\hline \multicolumn{5}{|l|}{ Depression } \\
\hline Yes & 273 & 96 & $4.16(2.89,5.98)$ & $1.92(1.16,3.19)^{*}$ \\
\hline No & 84 & 123 & 1.00 & 1.00 \\
\hline \multicolumn{5}{|l|}{ Stress } \\
\hline Yes & 238 & 84 & $3.21(2.27,4.56)$ & $2.04(1.26,3.31)^{* *}$ \\
\hline No & 119 & 135 & 1.00 & 1.00 \\
\hline \multicolumn{5}{|l|}{ Anxiety } \\
\hline Yes & 234 & 81 & $3.24(.2 .28,4.60)$ & $1.47(0.907,2.39)$ \\
\hline No & 123 & 138 & 1.00 & 1.00 \\
\hline \multicolumn{5}{|l|}{ Sleep hygiene } \\
\hline Poor & 205 & 72 & $2.75(1.94,3.91)$ & $3.01(1.75,5.18)^{* *}$ \\
\hline Good & 152 & 147 & 1.00 & 1.00 \\
\hline \multicolumn{5}{|l|}{ Social support } \\
\hline Poor & 208 & 72 & $2.08(1.33,3.25)$ & $5.39(2.33,12.49)^{* *}$ \\
\hline Moderate & 78 & 96 & $0.58(0.37,0.93)$ & $1.58(0.69,3.59)$ \\
\hline Strong & 71 & 51 & 1.00 & 1.00 \\
\hline CGPA & & & $0.195(0.14,0.27)$ & $0.19(0.13,0.28)^{* *}$ \\
\hline
\end{tabular}

N.B. 1.00 reference, ${ }^{*} p$-value less than $0.05,{ }^{* *} p$-value less than 0.001

which often deprive themselves from sleep to improve their grade. This creates a vicious cycle that is associated with an adverse effect on sleep quality. In addition that poor sleep might affect certain parts of the brain, especially the frontal and partial regions including subcortical structure such as basal ganglia and thalamus (Goel et al. 2009).

Regarding social support, participant who had poor social support were 5 times more likely to have poor sleep quality. This finding is in agreement with study done in Taiwan (Cheng et al. 2012). The possible reason might be students with low or poor social support have higher rate of mental distress than those with strong social support which may leads to sleep disturbance. Social support may also influence emotional regulation and emotional reactivity that implicate in the development of sleep problem (Jin et al. 2014).
The odd of having poor sleep quality was 3 times higher among participant with poor sleep hygiene as compared to those with good sleep hygiene. The finding of the current study coincides with study done in Iran in Qazvin university (Yazdi et al. 2016) and US (Brick et al. 2010). This is might be due to the fact that participants with poor sleep hygiene could have poor psychosocial functioning, diminished cognitive performance and deterioration of daily functioning which can affect normal sleep. Studies conducted in different countries showed that good sleep hygiene practice is important for good academic performance of students (BaHammam et al. 2012). This is might be due to stimulant drinking at evening for purpose of study affects melatonin hormone production. Other reason might be lack of regular activity, lack of regular sleep-awake schedule and going to bed without 
sleep sensation that disturb sleep pattern and leads to poor sleep quality (19).

In this study, no significant association was found between sex and sleep quality, in contrast a few studies did report that being a female medical student was significant predictor of high poor sleep quality (Ibrahim et al. 2017). In addition in this study no significant association was found anxiety and poor sleep quality. Finding is not in agreement with study done in Jeddah, Saudi Arabia (Ibrahim et al. 2017), The possible reason might be the previous studies focus on preclinical students, attributed to the high number of lectures, study load during the early pre-clinical years. The other reason might be participants might not adapt to environment.

\section{Limitation of the study}

The limitation of this study might be due to the nature of study design, which cannot establish temporal relationship between outcome and independent variables.

\section{Conclusion}

A high prevalence of poor sleep quality was prevailed among medical students in the current study. CGPA, stress, depression, poor sleep hygiene and poor social support were found to be significant factors associated with poor sleep quality. Institution based academic counseling center focusing on student's study skill and coping with their stressful environment is crucial. Moreover, it is better to educating medical students about proper sleep hygiene and the consequences of poor sleep practices. It would have been better conduct prospective study to investigate the cause effect relationship of risk factors of poor sleeps quality.

\section{Abbreviations}

DASS: Depression, Anxiety, Stress Scale; CGPA: Cumulative Grade Point Average; SHI: Sleep Hygiene Index; SPSS: Statistical Package for Social Sciences; PSQI: Pittsburgh Sleep Quality Index

\section{Acknowledgments \\ Authors of this study would like to acknowledge the staff of the Tikur Anbessa Specialized Hospital for their cooperation in giving information. Our sincere gratitude goes to University of Gondar, College of Medicine and Health Sciences, department of Psychiatry and Amanuel Mental Specialized Hospital, Research and Dissemination Office for funding the study. We also appreciate the study participants for their cooperation in providing the necessary information.}

\section{Authors' contributions}

TW conceived the research. She framed the methods, did the analysis, and wrote the final paper. HM, MB and WD participated in framing the method, data collection, and write-up. AM, DM and KY participated in framing the method, write-up and wrote the manuscript. All the authors read and agreed on the final manuscript.

\section{Funding}

Not Applicable.

\section{Availability of data and materials}

The datasets used and analyzed during the current study will be accessed from the corresponding author upon reasonable request.

\section{Ethics approval and consent to participate}

Ethical clearance was obtained from the joint ethical review committee of University of Gondar and Amanuel mental specialized hospital. Formal letter of permission was obtained from Amanuel mental specialized hospital and submitted to Tikur Anbessa medical school. Participants gave their written informed consent after adequate information about the study, and the potential benefits had been provided. Data was collected after obtaining written consent from participants.

\section{Consent for publication}

Not applicable.

\section{Competing interests}

The authors declare that they have no competing interests.

\section{Author details}

${ }^{1}$ Department of Psychiatry College of medicine and health science, Debre Markos University, Debre Markos, Ethiopia. ${ }^{2}$ Department of Psychiatry, College of Medicine and Health Sciences, Dilla University, Dilla, Ethiopia. ${ }^{3}$ Department of Psychiatry, School of Medicine, College of Medicine and Health Sciences, University of Gondar, Gondar, Ethiopia. ${ }^{4}$ Research and training department, Amanuel Mental Specialized Hospital, Addis Ababa, Ethiopia.

Received: 17 June 2020 Accepted: 1 February 2021

Published online: 03 March 2021

\section{References}

Abdulghani HM, Alrowais NA, Bin-Saad NS, Al-Subaie NM, Haji AM, Alhaqwi Al. Sleep disorder among medical students: relationship to their academic performance. Med Teach. 2012;34(sup1):S37-41.

Abiola T, Udofia O, Zakari M. Psychometric properties of the 3-item Oslo social support scale among clinical students of Bayero University Kano, Nigeria. Malays J Psychiatry. 2013;22(2):32-41.

Al-Humairi AK. Sleep quality and academic performance among medical college students. J Univ Babylon. 2018;26(3):142-52.

Almojali Al, Almalki SA, Alothman AS, Masuadi EM, Alaqeel MK. The prevalence and association of stress with sleep quality among medical students. J Epidemiol Glob Health. 2017;7(3):169-74.

Aloba OO, Adewuya AO, Ola BA, Mapayi BM. Validity of the Pittsburgh sleep quality index (PSQI) among Nigerian university students. Sleep Med. 2007; 8(3):266-70.

Altevogt BM, Colten HR. Sleep disorders and sleep deprivation: an unmet public health problem: National Academies Press; 2006.

Azad MC, Fraser K, Rumana N, Abdullah AF, Shahana N, Hanly PJ, Turin TC. Sleep disturbances among medical students: a global perspective. J Clin Sleep Med. 2015;11(1):69-74.

BaHammam AS, Alaseem AM, Alzakri AA, Almeneessier AS, Sharif MM. The relationship between sleep and wake habits and academic performance in medical students: a cross-sectional study. BMC Med Educ. 2012;12(1):61.

Berhanu H, Mossie A, Tadesse S, Geleta D. Prevalence and associated factors of sleep quality among adults in Jimma town, Southwest Ethiopia: a community-based cross-sectional study. Sleep Disord. 2018;2018:10.

Brick CA, Seely DL, Palermo TM. Association between sleep hygiene and sleep quality in medical students. Behav Sleep Med. 2010;8(2):113-21.

Brown FC, Soper B, Buboltz WC Jr. Prevalence of delayed sleep phase syndrome in university students. Coll Stud J. 2001;35(3):472-7.

Buysse DJ, Reynolds CF III, Monk TH, Berman SR, Kupfer DJ. The Pittsburgh sleep quality index: a new instrument for psychiatric practice and research. Psychiatry Res. 1989;28(2):193-213.

Cheng SH, Shih C-C, Lee IH, Hou Y-W, Chen KC, Chen K-T, Yang YK, Yang YC. A study on the sleep quality of incoming university students. Psychiatry Res. 2012;197(3):270-4.

Dahl RE, Lewin DS. Pathways to adolescent health sleep regulation and behavior. J Adolesc Health. 2002;31(6):175-84.

Dalgard OS, Dowrick C, Lehtinen V, Vazquez-Barquero JL, Casey P, Wilkinson G, Ayuso-Mateos JL, Page H, Dunn G, Group O. Negative life events, social support and gender difference in depression. Soc Psychiatry Psychiatr Epidemiol. 2006:41(6):444-51.

Dixon JB, Dixon ME, O'Brien PE. Depression in association with severe obesity: changes with weight loss. Arch Intern Med. 2003;163(17):2058-65. 
Ezquiaga A, Vas C, Nieto G, Blanco S, Schwemler M, Roca L, Garcia A, Prost J. Sleep quality evaluation in medical students. J Neurol Sci. 2015;357:e435.

Fawzy M, Hamed SA. Prevalence of psychological stress, depression and anxiety among medical students in Egypt. J Psychiatr Res. 2017;255:186-94.

Foley D, Ancoli-Israel S, Britz P, Walsh J. Sleep disturbances and chronic disease in older adults: results of the 2003 National Sleep Foundation Sleep in America Survey. J Psychosom Res. 2004;56(5):497-502.

Foster PG, Peirson SN, Wulff K, Winnebeck E, Vetter C, Roenneberg T. Sleep and circadian rhythm disruption in social jetlag and mental illness. In: Progress in molecular biology and translational science, vol. 119: Elsevier; 2013. p. 325-46.

Genzel L, Ahrberg K, Roselli C, Niedermaier S, Steiger A, Dresler M, Roenneberg T. Sleep timing is more important than sleep length or quality for medical school performance. Chronobiol Int. 2013;30(6):766-71.

Goel N, Rao H, Durmer JS, Dinges DF. Neurocognitive consequences of sleep deprivation. In: Seminars in neurology: 2009: @ Thieme Medical Publishers; 2009. p. 320-39.

Haseli-Mashhadi N, Dadd T, Pan A, Yu Z, Lin X, Franco OH. Sleep quality in middle-aged and elderly Chinese: distribution, associated factors and associations with cardio-metabolic risk factors. BMC Public Health. 2009; 9(1):130.

Hyyppä MT, Kronholm E. Quality of sleep and chronic illnesses. J Clin Epidemiol. 1989:42(7):633-8.

Ibrahim N, Badawi F, Mansouri Y, Ainousa A, Jambi S. Sleep quality among medical students at King Abdulaziz University: a cross-sectional study. J Community Med Health Educ. 2017;7(561):2161-711.

James BO, Omoaregba JO, Igberase OO. Prevalence and correlates of poor sleep quality among medical students at a Nigerian university. Ann Niger Med. 2011;5(1):1.

Jin Y, Ding Z, Fei Y, Jin W, Liu H, Chen Z, Zheng S, Wang L, Wang Z, Zhang S. Social relationships play a role in sleep status in Chinese undergraduate students. Psychiatry Res. 2014;220(1-2):631-8.

Kashani M, Eliasson A, Vernalis M. Perceived stress correlates with disturbed sleep: a link connecting stress and cardiovascular disease. J Therm Stresses. 2012; 15(1):45-51.

Kenney SR, LaBrie JW, Hummer JF, Pham AT. Global sleep quality as a moderator of alcohol consumption and consequences in college students. Addict Behav. 2012;37(4):507-12

Kessler RC, Andrews G, Mroczek D, Ustun B, Wittchen HU. The world health organization composite international diagnostic interview short-form (cidi-sf). Int J Methods Psychiatr Res. 1998;7(4):171-85.

Lemma S, Gelaye B, Berhane Y, Worku A, Williams MA. Sleep quality and its psychological correlates among university students in Ethiopia: a crosssectional study. BMC Psychiatry. 2012;12(1):237.

Lund HG, Reider BD, Whiting AB, Prichard JR. Sleep patterns and predictors of disturbed sleep in a large population of college students. J Adolesc Health. 2010a;46(2):124-32

Mastin DF, Bryson J, Corwyn R. Assessment of sleep hygiene using the sleep hygiene index. J Behav Med. 2006;29(3):223-7.

Mirghani HO, Mohammed OS, Almurtadha YM, Ahmed MS. Good sleep quality is associated with better academic performance among Sudanese medical students. BMC Res Notes. 2015;8(1):706

Mume CO, Olawale KO, Osundina AF. Excessive daytime sleepiness, nocturnal sleep duration and psychopathology among Nigerian university students. S Afr J Psychiatry. 2011;17(4):108-11.

Nadorff MR, Nazem S, Fiske A. Insomnia symptoms, nightmares, and suicidal ideation in a college student sample. Sleep. 2011;34(1):93-8.

Ozdemir PG, Boysan M, Selvi Y, Yildirim A, Yilmaz E. Psychometric properties of the Turkish version of the sleep hygiene index in clinical and non-clinical samples. Compr Psychiatry. 2015;59:135-40.

Pacheco JP, Giacomin HT, Tam WW, Ribeiro TB, Arab C, Bezerra IM, Pinasco GC. Mental health problems among medical students in Brazil: a systematic review and meta-analysis. Br J Psychiatry. 2017;39(4):369-78.

Priya J, Singh J, Kumari SJ, Res AM. Study of the factors associated with poor sleep among medical students. Indian J Basic. 2017;6:422-9.

Rathi A, Ransing RS, Mishra KK, Narula N. Quality of sleep among medical students: relationship with personality traits. J Clin Diagn Res. 2018;12(9):1-4.

Rodrigues RND, Viegas CA, Abreu e Silva AA, Tavares P. Daytime sleepiness and academic performance in medical students. Arq Neuropsiquiatr. 2002;60(1):6-11.

Sadock B, Ruiz P. Kaplan and sadock's synopsis of psychiatry behavioral sciences. In: Clinical Psychiatry 11th ed Wolters Kluwer Health; 2014.
Sahraian A, Javadpour A. Sleep disruption and its correlation to psychological distress among medical students. Shiraz E Med J. 2010;11(1):12-7.

Shad R, Thawani R, Goel A. Burnout and sleep quality: a cross-sectional questionnaire-based study of medical and non-medical students in India. Cureus. 2015;7(10):361.

Siddiqui AF, Al-Musa H, Al-Amri H, Al-Qahtani A, Al-Shahrani M, Al-Qahtani M. Sleep patterns and predictors of poor sleep quality among medical students in King Khalid University, Saudi Arabia. Malaysian J Med Sci. 2016;23(6):94.

Stranges S, Tigbe W, Gómez-Olivé FX, Thorogood M, Kandala N-B. Sleep problems: an emerging global epidemic? Findings from the INDEPTH WHOSAGE study among more than 40,000 older adults from 8 countries across Africa and Asia. Sleep. 2012;35(8):1173-81.

Surani AA, Zahid S, Surani A, Ali S, Mubeen M, Khan RH. Sleep quality among medical students of Karachi, Pakistan. J Pak Med Assoc. 2015a;65(4):380-2.

Szabó $M$. The short version of the depression anxiety stress scales (DASS-21): factor structure in a young adolescent sample. J Adolesc. 2010;33(1):1-8.

Van Reeth O, Weibel L, Spiegel K, Leproult R, Dugovic C, Maccari S. Interactions between stress and sleep: from basic research to clinical situations. J Sleep Med Rev. 2000a;4(2):201-20.

Vyazovskiy W. Sleep, recovery, and metaregulation: explaining the benefits of sleep. Nat Sci Sleep. 2015;7:171.

Waqas A, Khan S, Sharif W, Khalid U, Ali A. Association of academic stress with sleeping difficulties in medical students of a Pakistani medical school: a cross sectional survey. PeerJ. 2015:3:e840.

Wong J, Patil N, Beh S, Cheung E, Wong V, Chan L, Lieh Mak F. Cultivating psychological well-being in Hong Kong's future doctors. Med Teach. 2005; 27(8):715-9.

Yang C-M, Wu C-H, Hsieh M-H, Liu M-H, Lu F-H. Coping with sleep disturbances among young adults: a survey of first-year college students in Taiwan. Behav Med. 2003;29(3):133-8.

Yazdi Z, Loukzadeh Z, Moghaddam P, Jalilolghadr S. Sleep hygiene practices and their relation to sleep quality in medical students of Qazvin University of Medical Sciences. J Caring Sci. 2016;5(2):153.

Yeung W-F, Chung K-F, Cy Chan T. Sleep-wake habits, excessive daytime sleepiness and academic performance among medical students in Hong Kong. Biol Rhythm Res. 2008;39(4):369-77.

\section{Publisher's Note}

Springer Nature remains neutral with regard to jurisdictional claims in published maps and institutional affiliations.

\section{Ready to submit your research? Choose BMC and benefit from:}

- fast, convenient online submission

- thorough peer review by experienced researchers in your field

- rapid publication on acceptance

- support for research data, including large and complex data types

- gold Open Access which fosters wider collaboration and increased citations

- maximum visibility for your research: over $100 \mathrm{M}$ website views per year

At BMC, research is always in progress.

Learn more biomedcentral.com/submissions 